\title{
Comparative evaluation of push-out bond strength of a MTA-based root canal sealer
}

\author{
Eduardo Diogo Gurgel-Filho ${ }^{1}$, Felipe Martins Leite ${ }^{1}$, Jaírton Benício de Lima ${ }^{1}$, \\ João Paulo Chaves Montenegro ${ }^{1}$, Flávia Saavedra ${ }^{2}$, Emmanuel João Nogueira Leal Silva ${ }^{3}$
}

\author{
${ }^{1}$ Universidade de Fortaleza - UNIFOR, School of Dentistry, Department of Endodontics, Fotaleza, CE, Brazil \\ Universidade Estadual de Campinas - UNICAMP, School of Dentistry, Department of Restorative Dentistry, Piracicaba, SP, Brazil \\ ${ }^{3}$ UNIGRANRIO, School of Dentistry, Department of Endodontics, Rio de Janeiro, RJ, Brazil
}

\begin{abstract}
Aim: To evaluate the bond strength to root dentin of three root canal sealers: a mineral trioxide aggregate (MTA)-based sealer (MTA Fillapex ${ }^{\circledast}$ ), an epoxy resin-based sealer (AH Plus ${ }^{\circledR}$ ), and a zinc oxide eugenol-based sealer (EndoFill ${ }^{\mathbb{Q}}$ ). Methods: Thirty extracted single-root human teeth of similar sizes and circular canals were prepared using \#3 and \#2 Gates Glidden drills in the cervical portion of the canal and $K 3^{\circledR}$ rotary instruments to a size $\# 25 / 0.06$ to working length. Irrigation with $0.5 \mathrm{~mL} 2 \%$ chlorhexidine gel was used before and $1 \mathrm{~mL}$ saline after each instrument. The smear layer was removed with $3 \mathrm{~mL}$ 17\% EDTA for $3 \mathrm{~min}$. The samples were sectioned horizontally into eight $1 \pm 0.1 \mathrm{~mm}$-thick serial slices and then the push-out test was carried out. Two-way analysis of variance (ANOVA) and the post-hoc Tukey test were used for the analysis of the data with a significance level of $5 \%$. Results: AH Plus presented significantly higher bond strengths $(p<0.05)$ than the other sealers, while MTA Fillapex showed the lowest bond strengths $(p<0.05)$. Conclusions: The present study concluded that EndoFill ${ }^{\circledR}$ sealer and MTA FillApex ${ }^{\circledR}$ core combination were not superior to AH Plus ${ }^{\circledR}$ sealer and gutta-percha core combination.
\end{abstract}

Keywords: endodontics; root canal obturation; root canal filling materials.

\section{Introduction}

The aim of endodontic therapy is not only to eliminate microorganisms by cleaning and shaping the root canal, but also to ensure that the root canal system will be fluid free and that a single unit can be created by the filling material (cones and sealer) and root dentin walls.

Bond strength of endodontic sealers to dentin is an important property of filling materials because it minimizes the risk of filling detachment from dentin during restorative procedures or the masticatory function ${ }^{1}$, ensuring that sealing is maintained and, consequently, clinical success of endodontic treatment. The push-out bond strength test is a well-known evaluation method used in several

Received for publication: April 24, 2014

Accepted: June 03, 2014

Correspondence to: Emmanuel João Nogueira Leal da Silva Rua Herotides de Oliveira 61/902 CEP: 24230230 Niterói, Rio de Janeiro. Phone: +55 2183575757 E-mail: nogueiraemmanuel@hotmail.com other similar studies ${ }^{1-4}$ with great reliability. Thus, its results can be useful for inferring the interfacial strength and dislocation resistance between different root filling materials and the root dentin.

MTA Fillapex ${ }^{\circledR}$ (Angelus, Londrina, PR, Brazil), a sealer based on calcium silicate, was introduced recently on the market. After mixing, its composition is basically MTA, salicylate resin, natural resin, bismuth oxide and silica. The manufacturer claims that it has excellent radiopacity, easy handling, a good working time and low solubility, providing sealing of the canal by expansion 
Table 1. Tested sealers and their composition.

\begin{tabular}{|c|c|c|}
\hline Product and manufacturer & Composition & Preparation mode \\
\hline $\begin{array}{l}\text { EndoFill }{ }^{\oplus} \text { (Endo Fill, Dentsply Ind. e } \\
\text { Com. Ltda., Rio de Janeiro, RJ, Brazil) }\end{array}$ & $\begin{array}{l}\text { Powder: Zinc oxide, staybelite resin, bismuth subcarbonate, } \\
\text { barium sulfate, sodium borate anhydrate. Liquid: eugenol. }\end{array}$ & $\begin{array}{l}\text { The components were combined by } \\
\text { mixing the powder into liquid. }\end{array}$ \\
\hline $\begin{array}{l}\text { AH Plus }{ }^{\circledast} \quad \text { (Dentsply, Konstanz, } \\
\text { Germany) }\end{array}$ & $\begin{array}{l}\text { Paste A - bisphenol-A, bisphenol-F calcium tungstate, zirconium } \\
\text { oxide, silica iron oxide pigmentsPaste B - } \\
\text { dibenzyldiamineaminoadamantane tricyclodecane-diaminecalcium } \\
\text { tungstate, zirconium oxide, silica, silicone oil }\end{array}$ & $\begin{array}{l}\text { The components were mixed in equal } \\
\text { portions of pastes } \mathrm{A} \text { and } \mathrm{B} \text {. }\end{array}$ \\
\hline $\begin{array}{l}\text { MTA Fillapex }{ }^{\circledast} \text { (Angelus, Curitiba, PR, } \\
\text { Brazil) }\end{array}$ & $\begin{array}{l}\text { Salicylate resin, diluting resin, natural resin, bismuth trioxide, } \\
\text { nanoparticulated silica, MTA, pigments. }\end{array}$ & $\begin{array}{c}\text { The components were combined by } \\
\text { using a self-mixing tip attached to a } \\
\text { syringe. }\end{array}$ \\
\hline
\end{tabular}

during setting. Recent studies showed suitable radiopacity, $\mathrm{pH}$, flow, working and setting time of MTA Fillapex ${ }^{5-6}$. However, controversial results have been presented with respect to its bond strength to root dentin ${ }^{1-2}$. Sagsen et al. ${ }^{1}$ (2011) concluded that MTA Fillapex had the lowest pushout bond values to root dentin compared with an epoxybased root canal sealer and different calcium silicate-based root canal sealers. On the other hand, Assmann et al. ${ }^{2}$ (2012) stated that MTA Fillapex presented acceptable resistance to dislodgement, similar to that observed in samples filled with an epoxy-based root canal sealer.

The present study was designed to assess the bond strength of root fillings in canals obturated with MTA Fillapex. AH Plus ${ }^{\circledR}$ (Dentsply DeTrey GmbH, Konstanz, Germany) and EndoFill $^{\circledR}$ (Endo Fill; Dentsply Ind. e Com. Ltda., Rio de Janeiro, RJ, Brazil) were used as reference materials for comparison, and the push-out bond strength was the outcome variable. The null hypothesis tested is that there was no significant difference in the resistance to dislodgement of the root fillings in canals obturated with the different tested materials.

\section{Material and methods}

This study was approved by the local Ethics Committee (Protocol \#2011.1.373.58.3). Thirty extracted single-root human teeth of similar sizes and circular canals were randomly selected and stored in distilled water at $4{ }^{\circ} \mathrm{C}$. To standardize the working length, a size $15 \mathrm{~K}$-file (Dentsply-Maillefer, Ballaigues, Switzerland) was inserted into the root canal until it could be visualized at the apical foramen. The working length was determined by subtracting $1 \mathrm{~mm}$ from this length. After measurement, the length of all roots was standardized to $13 \mathrm{~mm}$ to prevent the introduction of confounders that could contribute to variations in the preparation procedures ${ }^{7}$.

All teeth were instrumented using \#3 and \#2 Gates Glidden drills in the cervical portion of the canal. Then, the root canals were instrumented using K3 rotary instruments (Sybron Endo) to a size \#25/0.06 to working length. Irrigation with $0.5 \mathrm{~mL} 2 \%$ chlorhexidine gel was used before each instrument and $1 \mathrm{~mL} 0.9 \%$ saline solution after each instrument. The smear layer was removed with $3 \mathrm{~mL} 17 \%$ EDTA for $3 \mathrm{~min}$. A total of $3 \mathrm{~mL}$ saline was used for $3 \mathrm{~min}$ as a final rinse. Each canal was dried with paper points.

Obturation procedures were performed using the single gutta-percha cone technique. Using a computer algorithm (http://www.random.org), the 30 roots were randomly assigned to 3 groups for obturation with one of the three sealers: $\mathrm{AH}$ Plus, EndoFill or MTA Fillapex. Composition of the sealers is shown in Table 1. The sealers were prepared according to the manufacturers' instructions. On completion of these procedures, the specimens were radiographed at different angles to verify the quality of the filling procedure and presence of bubbles. The specimens were placed in $100 \%$ humidity for 7 days to ensure complete setting of the sealer.

Afterwards, each root was sectioned horizontally into eight $1 \pm 0.1 \mathrm{~mm}$-thick serial slices by using a low-speed saw with a diamond disk under continuous water irrigation. The root filling of each sample was loaded with a $0.5-\mathrm{mm}$ diameter stainless steel cylindrical plunger. The plunger tip was sized and positioned to touch only the root filling. The load was always applied in an apical-coronal direction to avoid any constriction interference caused by root canal taper during push-out testing. Loading was performed on a universal testing machine (Instron Corporation, Norwood, MA, USA) at a crosshead speed of $0.5 \mathrm{~mm} / \mathrm{min}$ until debonding occurred. Each cross section was coded and measured for the apical and coronal diameters of the obturated area by using an optical stereomicroscope. A load/time curve was plotted during the compression test using real-time software. To express the bond strength in $\mathrm{MPa}$, the load at failure recorded in $\mathrm{N}$ was divided by the area of the bonded interface ${ }^{3}$.

The normality test of Shapiro-Wilkand and Levenes variance homogeneity tests were applied to the data showing normal distribution and homogeneity of variance among the groups. Two-way analysis of variance (ANOVA) and the posthoc Tukey test were used for the data analysis; the independent variables were root canal filling material and root canal third $(\mathrm{p}<0.05)$.

\section{Results}

All specimens showed measurable adhesive properties to root dentin. In addition, no premature failure occurred. Overall, the push-out bond strength was the highest in the coronal third and lowest in the apical third. AH Plus specimens 
displayed statistically higher bond strengths $(p=0.0012,0.51$ 5.9 MPa). MTA Fillapex showed the lowest bond strengths. The values of the push-out bond strength data in each experimental group are shown in Table 2.

Table 2. Push-out bond strength mean values (MPa) and standard deviation (SD) of the different root canal filling system to root dentin.

\begin{tabular}{ll}
\hline Group & Mean (SD)* \\
Endo Fill & $0.54 \pm 0.24^{\mathrm{A}}$ \\
AH-Plus $^{\circledR}$ & $3.80 \pm 1.90^{\mathrm{B}}$ \\
MTA Fill Apex $^{\circledR}$ & $0.25 \pm 0.10^{\mathrm{A}}$ \\
\hline
\end{tabular}

\section{Discussion}

Gutta-percha does not bond to root dentin and is used in conjunction with a root canal sealer ${ }^{1}$, so the adhesive properties of endodontic sealers are important. It was suggested that, if a material bonds to the root canal walls, it resists dislodgement of the filling ${ }^{8}$. It is also believed that chemical bonding to root dentin improves the push out bond strength of sealers to root canal walls ${ }^{9}$.

In this study, the push-out test was used to test the dentin bond strength of different root canal sealers. It has been suggested that this test provides a better evaluation of bond strength than the conventional shear test because in the pushout test, fracture occurs parallel to the dentin-bonding interface, which makes it a true shear test for parallel-sided samples ${ }^{7,10}$.

Extrusion testing in dentistry was first described by Roydhouse $^{11}$ (1970). Kimura, Shimizu and Fujii ${ }^{12}$ (1985) concluded that push-out testing tended to reduce the values for bond strength to dentin. Haller and Klaiber ${ }^{13}$ (1991) reintroduced the push-out test and the testing procedure selected for the present investigation used their model. The model has shown to be effective and reproducible. Another advantage of this method is that it allows root canal sealers to be evaluated even when bond strengths are low ${ }^{4}$.

During chemo-mechanical preparation, a layer of debris, the smear layer, is formed. Current theories of dentine bonding mechanisms involve either chemical modification of the smear layer and bonding directly to it, or removal of the smear layer and bonding to subjacent tooth structures ${ }^{4,14}$. Some studies have shown that removal of the smear layer enhances the adhesion of sealers to the root canal wall ${ }^{15-16}$. The smear layer can act as a reservoir or substrate for microorganisms ${ }^{17}$, and can also block the extension of sealer tags into the dentinal tubules, thereby decreasing micromechanical adhesion ${ }^{18}$. In the current study, $17 \%$ EDTA was used after instrumentation to remove the smear layer.

Chlorhexidine gluconate $(\mathrm{CHX})$ has been suggested as an alternative irrigation solution that could replace $\mathrm{NaOCl}$. CHX is a bactericidal solution because of its ability to precipitate and coagulate bacterial intracellular constituents ${ }^{19}$. The resin system seems to be sensitive to $\mathrm{NaOCl}^{20}$, as its use during root canal therapy reduced the bond strength ${ }^{21}$. The $\mathrm{NaOCl}$ acts to oxidize a component in the dentinal matrix that interferes with free radical propagation at the resin-dentin interface leading to lower bond strength ${ }^{22}$.

The bond strength after use of CHX gel and EDTA differs from that after the use of $\mathrm{NaOCl}$ solely ${ }^{23}$. The bond strength to pulp chamber dentin decreased when endodontic irrigation was performed with $5.25 \% \mathrm{NaOCl}$ either associated or not with $17 \%$ EDTA $^{24-25}$. Thus, the results of these articles support the use of chlorhexidine gluconate associated with EDTA as root canal irrigation in the present study.

MTA Fillapex is a new salicylate resin- and calcium silicate-based sealer. The manufacturer claims that this product provides long-term sealing capacity, high radioopacity and promotes deposition of hard tissue. It contains calcium silicate, salicylate resin, diluting resins, natural resin, nanoparticulated resin and bismuth trioxide. It is anticipated that release of calcium and hydroxyl ions from the set sealer will result in the formation of apatite when the material comes into contact with phosphate-containing fluids ${ }^{25}$.

In the light of the results, the null hypothesis that there was no difference between the groups was rejected. The pushout bond strength of $\mathrm{AH}$ Plus was statistically superior to that of MTA Fillapex and Endo Fill. No statistically significant difference was found between MTA Fillapex and Endo Fill. This result corroborates those of Pécora et al. ${ }^{16}$ (2001) and Cecchin et al. ${ }^{26}$ (2012). They also found higher bond strength values for epoxy resin-based cements, like AH Plus, compared with zinc oxide-eugenol sealers, like Endo Fill. Several other studies also found that the push-out bond strength of AH Plus was superior to that of other root canal sealers ${ }^{27-29}$.

In the present study, the MTA-based sealer MTA Fillapex had the lowest bond strength to root dentin. Sarkar et $a .^{25}$ (2005) suggested that release of calcium and hydroxyl ions from the set sealer will result in the formation of apatite as the material comes into contact with phosphate-containing fluids. Reyes-Carmona et al. ${ }^{30}$ (2009), reported that the apatite formed by MTA and phosphate buffered saline was deposited within collagen fibrils, promoting controlled mineral nucleation on dentin, seen as the formation of an interface layer with tag-like structures. The reason for the low bond strength of MTA Fillapex in the present study could be the low adhesion capacity of these tag-like structures, corroborated by the study made by Sagsen et al. ${ }^{1}$ (2011). Although previous studies have already shown that MTA Fillapex had weak bond strength to the dentin wall, this fact is not normally expected, once this sealer has MTA as one of its ingredients and some of the well-known components of sealers. MTA properties are good adhesion to dentin walls, adequate seal and resistance to dislodgement ${ }^{5}$.

The adhesion of Grossman type root canal sealers to dentin is established by electrostatic bonding and not by its penetration into the dentinal tubules ${ }^{16}$. The low bond strength established with Group 1 may be explained by a chelating reaction that occurs while the zinc oxide-eugenol mixture is setting ${ }^{31}$. This reaction affects both the gutta-percha core material and the root canal dentin. The zinc ion of the zinc oxide may react with the mineral component of the dentin 
as well as with the zinc oxide constituent of gutta-percha. Also, eugenol may have a softening effect on gutta-percha, thus creating an interlocking meshwork that will increase adhesion between the materials.

Adhesive strength is only one aspect of the quality of root canal sealing, but it may be considered one of the most important. Currently, there are several different types of endodontic sealers available, but as shown by this study, not all of them have the best properties to ensure endodontic success. Further investigation of other features of root canal sealers is required. In most cases, the results of laboratory experimental studies cannot be directly applied to clinical situations ${ }^{4}$. However, they do provide reproducible and reliable means for comparing and testing new and prospective sealers, and for establishing international standards.

Within the limits of the push-out test method, in the present study, EndoFill sealer and MTA FillApex core combination were not superior to AH Plus sealer and guttapercha core combination. On the basis of the findings presented herein it may be concluded that AH Plus Sealer might provide an advantage over other sealers with respect to bond strength to root dentin.

\section{References}

1. Sagsen B, Ustün Y, Demirbuga S, Pala K. Push-out bond strength of two new calcium silicate-based endodontic sealers to root canal dentine. Int Endod J. 2011; 44: 1088-91.

2. Assmann E, Scarparo RK, Böttcher DE, Grecca FS. Dentin bond strength of two mineral trioxide aggregate-based and one epoxy resin-based sealers. J Endod. 2012; 38: 219-21.

3. Nagas E, Cehreli ZC, Durmaz V, Vallittu PK, Lassila LV. Regional push-out bond strength and coronal microleakage of Resilon after different light-curing methods. J Endod. 2007; 33: 1464-8.

4. Ungor M, Onay EO, Orucoglu H. Push-out bond strengths: the EpiphanyResilon endodontic obturation system compared with different pairings of Epiphany, Resilon, AH Plus and gutta-percha. Int Endod J. 2006; 39: 643-7.

5. Vitti RP, Prati C, Silva EJ, Sinhoreti MA, Zanchi CH, de Souza e Silva MG, et al. Physical properties of MTA Fillapex sealer. J Endod. 2013; 39: 915-8

6. Silva EJ, Rosa TP, Herrera DR, Jacinto RC, Gomes BP, ZaiaAA. Evaluation of cytotoxicity and physicochemical properties of calcium silicate-based endodontic sealer MTAFillapex. J Endod. 2013; 39: 274-7.

7. Drummond JL, Sakaquchi RL, Racean DC, Wozny J, Steinberg AD. Testing mode and surface treatment effects on dentin bonding. J Biomed Mater Res. 1996; 32: 533-41.

8. Shipper G, Ørstavik D, Teixeira FB, Trope M. An evaluation of microbial leakage in roots filled with a thermoplastic synthetic polymer-based root canal filling material (Resilon). J Endod. 2004; 30: 342-7.

9. Onay EO, Ungor M, Ari H, Belli S, Ogus E. Push-out bond strength and SEM evaluation of new polymeric root canal fillings. Oral Surg Oral Med Oral Pathol Oral Radiol Endod. 2009; 107: 879-85.

10. Ureyen Kaya B, Keceli AD, Orhan H, Belli S. Micropush outbond strengths of gutta-percha versus thermoplastic synthetic polymer-based systems an ex vivo study. Int Endod J. 2008; 41: 211-8.

11. Roydhouse RH. Punch-shear test for dental purposes. J Dent Res. 1970; 49: 131-6

12. Kimura S, Shimizu T, Fujii B. Influence of dentin on bonding of composite resin. Part 1. Effect of fresh dentin and storing conditions. Dent Mater J. 1985; 4: 68-80.
13. Haller B, Klaiber B. Adhesive cementation: prevention of pulp irritation. Phillip J. 1991; 8: 373-5.

14. Yu XY, Joynt RB, Davis EL, Wieczkowski Jr G. Adhesion to dentine. J Calif Dent Assoc. 1993; 21: 23-9.

15. De Gee AJ, Wu MK, Wesselink PR. Sealing properties of Ketac-Endo glass ionomer cement and AH26 root canal sealers. Int Endod J. 1994; 27: 239-44.

16. Pécora JD, Cussioli AL, Gueriooli DM, Marchesan MA, Sousa-Neto $M D$, Brugnera Júnior A. Evaluation of Er: YAG laser and EDTAC on dentin adhesion of six endodontic sealers. Braz Dent J. 2001; 12: 27-30.

17. Pashley DH. Smear layer: physiological considerations. Oper Dent Suppl. 1984; 3: 13-29.

18. Kouvas V, Liolios E, Vassiliadis L, Parissis-Messimeris S, Boutsioukis A. Influence of smear layer on depth of penetration of three endodontic sealers: an SEM study. Endod Dent Traumatol. 1998; 14: 191-5.

19. Ferraz CC, Gomes BP, Zaia AA, Teixeira FB, Souza-Filho FJ. In vitro assessment of the antimicrobial action and the mechanical ability of chlorhexidine gel as an endodontic irrigant. J Endod. 2001; 27: 452-5.

20. Hashem AA, Ghoneim AG, Lutfy RA, Fouda MY. The effect of different irrigating solutions on bond strength of two root canal-filling systems. J Endod. 2009; 35: 537-40.

21. Gonçalves L, Silva-Sousa YT, Raucci Neto W, Teixeira CS, SousaNeto MD, Alfredo E. Effect of different irrigation protocols on the radicular dentin interface and bond strength with a metacrylate-based endodontic sealer. Microsc Res Tech. 2014; 9: 1-7.

22. Weston $\mathrm{CH}$, Ito $\mathrm{S}$, Wadgaonkar $\mathrm{B}$, Pashley $\mathrm{DH}$. Effects of time and concentration of sodium ascorbate on reversal of $\mathrm{NaOCl}$-induced reduction in bond strengths. J Endod. 2007; 33: 879-81.

23. Santos JN, Carrilho MR, De Goes MF, Zaia AA, Gomes BP, SouzaFilho FJ, et al. Effect of chemical irrigants on the bond strength of a selfetching adhesive to pulp chamber dentin. J Endod. 2006; 32: 1088-90.

24. Liu C, Liu H, Zhu S. Effect of different irrigating solutions on bonding strength of fiber post to root canal. Hua Xi Kou Qiang Yi Xue Za Zhi. 2011; 29: 210-3.

25. Sarkar NK, Caicedo R, Ritwik P, Moiseyeva R, Kawashima I. Physicochemical basis of the biologic properties of mineral trioxide aggregate. J Endod. 2005; 31: 97-100.

26. Cecchin D, Souza M, Carlini-Júnior B, Barbizam JV. Bond strength of Resilon/Epiphany compared with gutta-percha and sealers Sealer 26 and Endo Fill. Aust Endod J. 2012; 38: 21-5.

27. Rosa RA, Barreto MS, Moraes R do A, Broch J, Bier CA, Só MV, et al. Influence of endodontic sealer composition and time of fiber post cementation on sealer adhesiveness to bovine root dentin. Braz Dent J. 2013; 24: 241-6.

28. Patil SA, Dodwad PK, Patil AA. An in vitro comparison of bond strengths of gutta-percha/AH Plus, Resilon/Epiphany self-etch and EndoREZ obturation system to intraradicular dentin using a push-out test design. J Conserv Dent. 2013; 16: 238-42.

29. Al Batouty KM, HashemAA. Push-out bond strength of a newly introduced glass fiber root canal filling material. J Adhes Dent. 2013; 15: 161-6.

30. Reyes-Carmona JF, Felippe MS, Felippe WT. Biomineralization ability and interaction of mineral trioxide aggregate and white portland cement with dentin in a phosphate-containing fluid. J Endod 2009; 35: 731-6.

31. Crisp S, Ambersley M, Wilson AD. Zinc oxide eugenol cements. V. Instrumental studies of the catalysis and acceleration of the setting reaction. J Dent Res. 1980; 59: 44-54. 